\title{
Beyond spreading activation: An influence of relatedness proportion on masked semantic priming
}

\author{
GLEN E. BODNER \\ University of Calgary, Calgary, Alberta, Canada \\ and \\ MICHAEL E. J. MASSON \\ University of Victoria, Victoria, British Columbia, Canada
}

\begin{abstract}
Semantic priming in the lexical decision task has been shown to increase when the proportion of related-prime trials is increased. This finding typically is taken as evidence for a conscious, strategic use of primes. Three experiments are reported in which masked semantic primes displayed for only 45 msec were tested in high- versus low-relatedness proportion conditions. Relatedness proportion was increased either by using a high proportion of semantically related primes or a large set of repetitionprimed filler trials. Semantic priming was consistently enhanced relative to a low-relatedness proportion condition. These relatedness proportion effects were not due to conscious, strategic use of primes: Exclusion of prime-aware subjects did not attenuate the effects, and better performance in a prime classification task was not associated with larger semantic priming effects. These results are interpreted within a retrospectiveaccount of semantic priming in which recruitment of a prime event is modulated by prime validity.
\end{abstract}

Theories of the organization and retrieval of semantic knowledge have been informed in large part by empirical demonstrations of the influence of semantically related primes on word identification(e.g., Anderson, 1983; Collins $\&$ Loftus, 1975). Many examples of this influence have been generated since the classic demonstration of semantic priming by Meyer, Schvaneveldt, and Ruddy (1975), in which faster responses to a target word are made if that word follows a semantically related word rather than an unrelated word (see Neely, 1991, for a review). Beneficial effects of semantic priming are typically ascribed to an activation process whereby presentation of a prime word activates semantic knowledge about not only that word but also other semantically related words, typically through a process of automatic spreading activation (Anderson, 1983; Collins \& Loftus, 1975; McNamara, 1992).

It is apparent, however, that automatic spreading activation is not the only means of generating semantic priming. Evidence for alternative sources of priming is provided by experiments in which the proportion of trials that present a semantically related prime is varied across dif-

This research was supported by the Natural Sciences and Engineering Research Council of Canada through a postgraduate scholarship and a research grant to G.E.B. and research and equipment grants to M.E.J.M. We are grateful to Jennifer Stolz, Derek Besner, Manuel Perea, and an anonymous reviewer for helpful suggestions. Correspondence should be addressed to G. E. Bodner, Department of Psychology, University of Calgary, 2500 University Drive NW, Calgary, AB T2N 1N4, Canada (e-mail: bodner@ucalgary.ca). ferent groups of subjects. This manipulation of relatedness proportion (RP) leads to variation in the size of priming effects such that larger priming effects are found when RP (and hence prime validity) is high and when the primetarget stimulus onset asynchrony (SOA) is at least $300 \mathrm{msec}$ (e.g., Henik, Friedrich, Tzelgov, \& Tramer, 1994; Hutchison, Neely, \& Johnson, 2001; Neely, Keefe, \& Ross, 1989; Stolz \& Neely, 1995). Automatic spreading activation should spread to the same extent regardless of list-wide $\mathrm{RP}$, so an additional process that influences priming must be postulated to explain the RP effect on priming.

Two processes have been proposed as accounts of the influence of RP. One is an expectancy process whereby subjects generate a likely identity for an upcoming target and the other is a semantic matching strategy in which subjects notice and use relationships between primes and targets to influence lexical decisions (Neely, 1991; Neely et al., 1989). Both processes are assumed to be consciously deployed strategies, and this assumption is supported by the finding that RP effects are typically absent when the SOA is less than $300 \mathrm{msec}$ (e.g., Hutchison et al., 2001; Perea \& Rosa, 2002; Stolz \& Neely, 1995). This constraint has led Neely and colleagues to consider RP effects on semantic priming to be the "signature" of a consciously controlled strategy such as expectancy or semantic matching (e.g., Hutchison et al., 2001; Neely, 1991; Neely et al., 1989; but see Stolz \& Neely, 1995).

Accounts of semantic priming as a product of prospective influences of a related prime (automatic spreading activation or expectancy strategy) and/or a retrospective se- 
mantic matching strategy have been challenged by accounts of priming that emphasize a retrospective memory retrieval process as the basis for priming. On these retrospective accounts, either the prime and target are integrated to form a compound long-term memory retrieval cue (Ratcliff \& McKoon, 1988) or the prime event creates a memory resource that can be recruited during target presentation to aid in the encoding of the target (Bodner \& Masson, 1997, 2001; Whittlesea \& Jacoby, 1990). The latter account led Bodner and Masson (2001) to examine the effect of proportion manipulations on repetition priming at very short SOAs. They reasoned that if priming were the result of retrospective recruitment of a form of episodic memory for a prime event, then that recruitment should be sensitive to a contextual influence such as RP (e.g., Allen \& Jacoby, 1990; Jacoby, 1983). High RP creates a context in which reliance on priming episodes is especially useful because those episodes usually contain information that will be relevant for the processing of the corresponding target. Using masked repetition primes with SOAs as low as $45 \mathrm{msec}$, Bodner and Masson (2001) found substantially larger priming effects when a high proportion (.8) rather than a low proportion (.2) of trials used repetition primes.

The episodic account, which assumes that RP influences the extent to which prime events are used to guide target processing, predicts that greater reliance on priming episodes when RP is high rather than low should generally produce a bias effect. That is, increased RP should reduce response latency on related-prime trials (given the semantic overlap between prime and target) and increase latency on unrelated-prime trials (given the potential for interference from an unrelated prime). Although this bias pattern was not clearly observed in each experiment reported by Bodner and Masson (2001), it was reliable when averaged across eight sets of data showing an RP effect. Of course, when repetition primes are used to increase prime validity, the cognitive system may also tune into orthographic, phonological, or other forms of overlap between primes and targets (e.g., Masson \& Isaak, 1999).

Building on this demonstration of RP effects on masked repetition priming, we hypothesized that $\mathrm{RP}$ effects of the same form might be found with masked semantic primes. Although masked semantic priming tends to be smaller than masked repetition priming, it can occur in the lexical decision task with SOAs of less than $70 \mathrm{msec}$ (Perea \& Gotor, 1997; Sereno, 1991). We note that failures to find RP effects with brief semantic primes involved unmasked primes (Hutchison et al., 2001; Stolz \& Neely, 1995). It is possible that conscious awareness of briefly presented primes might be experienced as distracting rather than helpful by most subjects (Durante \& Hirshman, 1994; Fischler \& Goodman, 1978). The one exception to this rule is a study by Perea and Rosa (2002), who failed to find an effect of RP on masked semantic priming at SOAs of 66, 116 , or $166 \mathrm{msec}$. Unfortunately, prime awareness was not assessed in these experiments, and it seems likely with these SOAs that many of their subjects would have been aware of the primes.
In the experiments reported here, we used a strong RP manipulation (.8 vs. .2) of masked semantic primes and a $45-\mathrm{msec} \mathrm{SOA}$ as a strong test of the claim that RP effects on semantic priming are necessarily the product of consciously controlled strategies (Neely, 1991; Neely et al., 1989). The use of masked primes and a 45 -msec SOA should exclude the possibility of deliberate, strategic use of primes and should prevent most subjects from noticing and hence from being distracted by the primes. On the expectancy and semantic matching accounts of RP effects, RP should not affect masked semantic priming. On the episodic account, greater use of the primes under high RP should elevate semantic priming relative to when $\mathrm{RP}$ is low.

\section{EXPERIMENT 1}

Two versions of Experiment 1 were conducted; the second was a replication of the first but also included an assessment of prime awareness. In both versions, we tested whether masked semantic priming would be affected by the proportion of related prime-target trials in the stimulus list. A low-RP group received related primes on 2 of the word trials, and a high-RP group received related primes on .8 of the word trials. For both groups, unrelated primes preceded the remaining word targets. To be compatible with studies of RP effects with plainly visible semantic primes, word primes preceded all nonword targets. A 45-msec prime SOA was used.

The assessment of prime awareness used in Experiment 1B involved a separate block of trials on which subjects classified a masked prime as a word or nonword and then attempted to report the prime. By directing attention to the prime instead of the target, this method likely overestimates subjects' awareness of primes during the usual lexical decision task. This type of prime awareness task, however, is frequently used in masked priming experiments (e.g., Dehaene et al., 1998; Kouider \& Dupoux, 2001; Naccache \& Dehaene, 2001) and may provide useful data beyond subjects' self-reports.

\section{Method}

Subjects. In Experiment 1A, 100 undergraduate students at the University of Victoria received extra course credit for their participation. In Experiment 1B, 50 subjects were tested; 21 were drawn from the population used in Experiment $1 \mathrm{~A}$ and the remainder were undergraduates from the University of Calgary who also received extra credit for their participation. For each experiment, half of the subjects were randomly assigned to each RP group (low vs. high).

Materials and Design. The critical targets were 200 words, three to eight letters in length, that ranged in frequency from 1 to 2,216 per million (median $=34$; Kučera \& Francis, 1967). Each word target was paired with a prime that had a related meaning (e.g., breadBUTTER, robin-BIRD, dusk-DAWN). Unrelated prime-target pairs were formed by assigning primes to unrelated targets. A set of 200 pronounceable nonwords of three to eight letters in length was constructed and an unrelated word prime was selected for each one.

The critical targets were divided into five blocks of 40 items for counterbalanced assignment to prime conditions. In the high-RP group, targets in four blocks were paired with related primes and targets in the other block were paired with unrelated primes $(\mathrm{RP}=.8)$. The reverse arrangement was used for the low-RP group $(\mathrm{RP}=.2)$. A set of 20 words and 20 nonwords was constructed for practice tri- 
als, each with a word prime. The RP of the practice items matched that of the critical items.

For the prime awareness task of Experiment 1B, a set of 50 target words, each with one unrelated word and one unrelated nonword prime, was constructed. For each subject, a randomly selected half of the word targets were paired with the word prime, and the rest were paired with the nonword prime.

Procedure. Subjects were tested individually using a Macintosh computer. A four-letter word subtended a visual angle of $1.4^{\circ}$ when viewed from a distance of $40 \mathrm{~cm}$. Subjects were told that several briefly displayed items would be shown on each trial in the center of the monitor and that their task was to classify the uppercase target as a word or nonword as quickly and as accurately as possible by pressing one of two designated keys. They were not specifically told about the primes. Each trial began with a 495 -msec pre-mask, followed by a 45 -msec prime in lowercase, then a target in uppercase that remained in view until the subject responded. Because primes and targets were often of different lengths, a row of $10 \mathrm{Xs}$ was used as the pre-mask and targets were flanked by as many ampersands as necessary to make a 10 -character string (e.g., \&\&VELVET\&\&) to minimize prime perceptibility. Note that this target display likely increased target processing difficulty, which could boost masked priming (e.g., Bodner \& Masson, 1997). A feedback message appeared on the monitor for $1 \mathrm{sec}$ and a tone sounded on trials where the subject made an incorrect response or took more than $1,500 \mathrm{msec}$ to respond. The intertrial interval was $500 \mathrm{msec}$.

The 40 practice trials were presented in random order followed by 400 critical trials also in random order. A rest break was provided after every 50 critical trials. After the lexical decision task, subjects were asked what they had seen on each trial just before the target appeared. If they initially reported seeing only the mask, which was a typical response, they were asked follow-up questions (e.g., "Did you see something else, after the row of Xs but before the target appeared?"). In Experiment 1B, subjects were then given 50 prime identification trials that followed the same display sequence as the lexical decision task. Subjects were now required to make a lexical decision response to the masked prime and then attempt to identify the prime. Subjects were informed that half of the primes would be words and half nonwords, and they were encouraged to make their best guess if they could not see a prime.

\section{Results}

Word targets. Trials with response latency shorter than $300 \mathrm{msec}$ or longer than $1,500 \mathrm{msec}$ (fewer than $0.5 \%$ ) were excluded (Ulrich \& Miller, 1994). Mean response latency and error percent for word targets in the lexical decision task are shown in Figure 1 for each version of Experiment 1 . Separate analyses of variance (ANOVAs) with $\mathrm{RP}$ group (low, high) and prime (related, unrelated) as factors were computed for each measure. Effects were significant at the $p<.05$ level unless otherwise noted.

In Experiment 1A, response latency was not reliably different in the two RP groups $(F<1)$, but responses were $19 \mathrm{msec}$ faster following related primes than following unrelated primes $\left[F(1,98)=57.59, M S_{\mathrm{e}}=308\right]$. Most important, the priming effect was larger in the high-RP group than in the low-RP group ( 24 vs. $14 \mathrm{msec})[F(1,98)=4.32$, $\left.M S_{\mathrm{e}}=308\right]$. In the error rate analysis, fewer errors were made on related trials $\left[F(1,98)=7.66, M S_{\mathrm{e}}=8.2\right]$, and fewer errors were made by the low-RP group $[F(1,98)=4.97$, $\left.M S_{\mathrm{e}}=16.3\right]$. These two factors did not interact $(F<1)$.

The interaction between RP and priming was replicated in Experiment 1B. The 24-msec semantic priming effect in the high-RP group was reliably greater than the 10-ms effect in the low-RP group $\left[F(1,48)=6.97, M S_{\mathrm{e}}=162\right]$. The overall priming effect was robust $[F(1,48)=43.96$, $\left.M S_{\mathrm{e}}=162\right]$, and there was no overall difference in response latency between the two RP groups $(F<1)$. The only reliable effect in the error rate analysis was a reduction in errors on related trials relative to unrelated trials $[F(1,48)=$ $\left.16.97, M S_{\mathrm{e}}=7.0\right]$ (other $F \mathrm{~s}<1.14$ ).

Nonword targets. The mean response latency for nonwords was $763 \mathrm{msec}$ for Experiment 1A and $720 \mathrm{msec}$ for Experiment 1B. The corresponding mean error rates were $6.3 \%$ and $6.2 \%$. In neither version of the experiment did $\mathrm{RP}$ have an influence on these measures $\left(F_{\mathrm{S}}<1\right)$.

Prime awareness. According to their reports, $26 \%$ of the low-RP group and 32\% of the high-RP group in Experiment 1 A were "prime aware," which we defined as having at least some awareness that something had been presented between the mask and target displays (e.g., a "flickering"). Only five prime-aware subjects reported noticing that some of the primes were related to their targets. Although prime-aware subjects often reported that their minimal awareness of the primes was distracting, the influence of RP on priming that we obtained might nonetheless be attributable to these subjects. Contrary to this possibility, when all prime-aware subjects were excluded, the semantic priming advantage for the high-RP group over the low-RP group was somewhat larger than in the entire group of subjects ( $25 \mathrm{vs} .10 \mathrm{msec})$ and was significant $\left[F(1,69)=8.09, M S_{\mathrm{e}}=237\right]$. There were no reliable effects in the corresponding error rate analyses $\left(F_{\mathrm{S}}<\right.$ $1.65)$.

In Experiment 1B, 4 subjects in the low-RP group $(20 \%)$ and 5 subjects in the high-RP group $(25 \%)$ reported at least minimal awareness of the primes. When these subjects were removed from the analysis of RP effects, mean priming scores for the high- and low-RP groups were still statistically significant $(24$ vs. $12 \mathrm{msec})[F(1,39)=4.41$, $\left.M S_{\mathrm{e}}=179\right]$.

Due to experimenter error, only 44 of the 50 subjects in Experiment 1B (22 per RP group) completed the prime classification and identification task. Subjects reported finding the task extremely challenging but were encouraged by the experimenter to make their best guesses. Accuracy in classifying the primes as words or nonwords was assessed by computing the proportion of word responses made to each type of prime (hits for word primes and false alarms for nonword primes). A $2 \times 2$ ANOVA with RP (low vs. high) and prime (word, nonword) revealed that the probability of a word response was significantly greater for word than for nonword primes (.62 vs. .50) $\left[F(1,42)=22.10, M S_{\mathrm{e}}=139\right]$. Thus, on average, subjects were able to make above-chance lexical judgments about the primes. The effect of prime type did not interact with RP $(F<1)$. In addition, 29 of the 44 subjects $(66 \%)$ identified at least 1 of the 25 word primes. The mean proportion of identified primes was similar for the low- and highRP groups (22\% and $17 \%$, respectively; $F<1$ ). One subject correctly identified one nonword prime. 


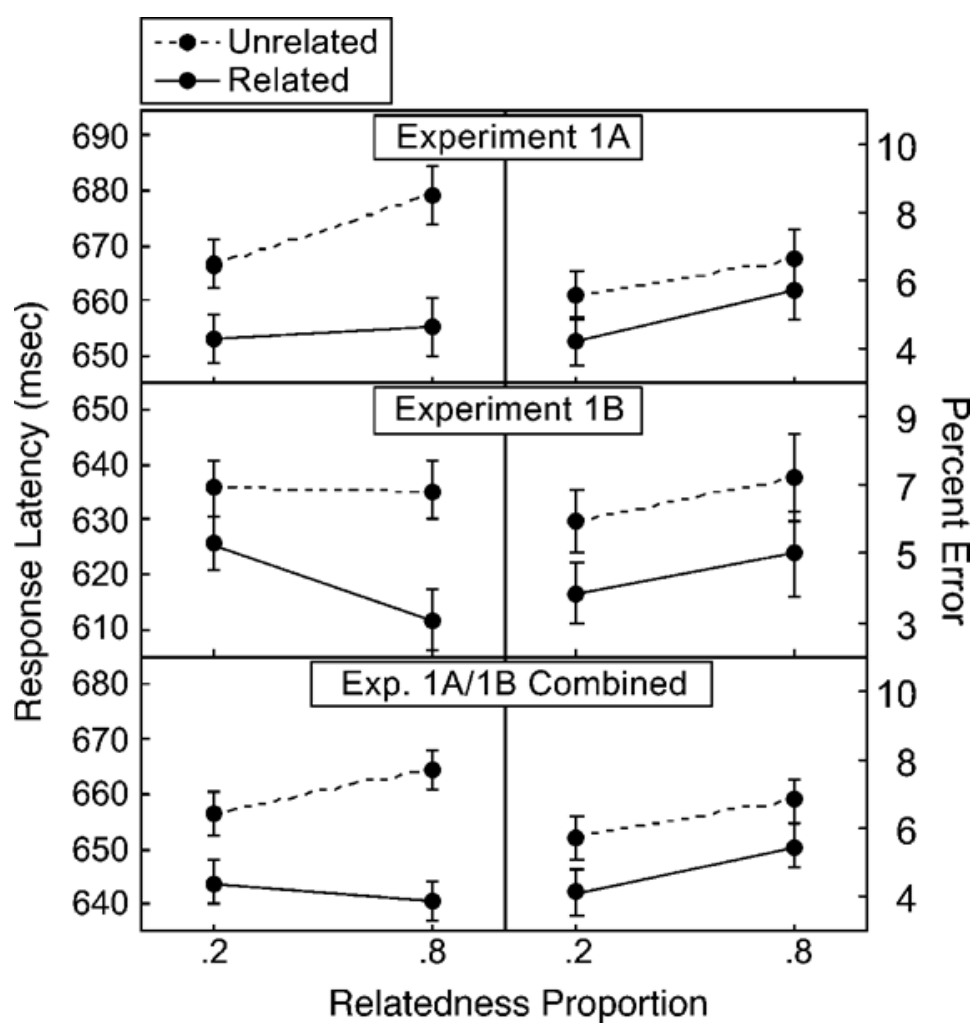

Figure 1. Mean response latency and percent error for words in Experiment 1. Error bars in the response time and percent error panels are $95 \%$ within-subjects confidence intervals (Loftus \& Masson, 1994) and are appropriate for comparing means across prime conditions within each RP group.

We computed two correlations to assess the possibility that variation in prime awareness, as measured by the prime classification and identification task, was related to the amount of masked semantic priming. The correlation between semantic priming and word-nonword prime classification was not significant $[r(42)=-.21, p<.17]$, and the correlation between semantic priming and prime identification approached significance $[r(42)=-.26$, $p<.10]$. Importantly, both correlations were negative, indicating that greater prime awareness, if anything, tended to be associated with less semantic priming.

\section{Discussion}

Experiment 1 is the first published report of an influence of RP on masked, short-SOA semantic priming: Subjects given a higher proportion of semantic prime trials showed increased semantic priming. This influence of list context is consistent with the proposal that high RP increases recruitment of masked prime episodes. It cannot be attributed to automatic spreading activation, a process that has no theoretical basis for being sensitive to RP. Nor can it be attributed to consciously controlled processes such as expectancy and semantic matching, because (1) these processes did not have nearly enough time to operate (Neely, 1991; Neely et al., 1989), and (2) the RP $\times$ prim- ing interaction was not attenuated when prime-aware subjects were excluded from the analysis. We suspect that inconsistent reports of RP effects on semantic priming at short SOAs may have arisen in part because some subjects find awareness of briefly presented primes to be distracting (see, e.g., Durante \& Hirshman, 1994; Fischler \& Goodman, 1978), which could work to obscure a potential influence of RP on priming.

There are a number of reasons to believe that the RP effect we have obtained is unlikely to have arisen because of awareness of primes. First, according to their responses to the prime awareness question, few subjects identified any of the primes during the lexical decision phase. Second, removing subjects who reported any degree of prime awareness did not diminish the size of the RP effect on priming. Third, in the prime classification and identification task of Experiment 1B, many subjects who claimed they were merely guessing were genuinely surprised when shown a summary of their results. As Naccache and Dehaene (2001) have pointed out, above-chance performance on a prime classification task does not necessarily imply conscious awareness of the primes; this performance may well be affected by contributions from unconscious processes. Fourth, there was no indication that greater prime awareness was associated with greater semantic priming. 
By the episodic account we are advocating, recruitment of priming episodes is likely to increase when high prime validity is detected by the cognitive system. Bodner and Masson (2001) supported this proposal by showing that increased reliance on repetition primes by subjects in their high-RP groups produced a bias effect: Responses benefited on the valid $80 \%$ of trials, but were impaired on the invalid $20 \%$ of trials, relative to the responses of the lowRP group. Figure 1 suggests that high RP in Experiment 1A increased response latencies on unrelated trials, but produced no corresponding benefit on related trials, relative to low RP. The fact that a symmetrical pattern of costs and benefits characteristic of a bias effect was not observed in this experiment may seem problematic for the episodic account. Caution must be exercised, however, when interpreting such patterns on the basis of the sample sizes typical of single experiments. There is substantial betweengroups variability that can greatly affect the response time differences between low- and high-RP groups without affecting the interaction between RP and priming. This point is made clear by examining the pattern of data shown in Figure 1 for Experiment 1B. In this case, the trend was for the high-RP group to be faster than the low$\mathrm{RP}$ group on related-prime trials with little difference on unrelated-prime trials. Combining across the two versions of Experiment 1 yields a pattern, shown in the lower section of Figure 1, characteristic of the bias interpretation of $\mathrm{RP}$ effects. The latency difference between RP groups is not reliable for either the related- or unrelated-prime condition because there is not enough power with this sample size to detect such small between-groups effects. We note that Bodner and Masson (2001) pooled data from eight experiments involving 380 subjects to obtain reliable differences in a repetition priming paradigm.

\section{EXPERIMENT 2}

Prime validity, as instantiated by RP, can have a modulating influence on both masked repetition priming (Bodner \& Masson, 2001) and masked semantic priming (Experiment 1). The cognitive system appears to be sensitive to the validity of masked primes and can increase or decrease its reliance on them accordingly. The purpose of Experiment 2 was to determine whether the increase in priming produced by high prime validity represents a general elevation in the use of the prime resource-whatever its relation to the target-or whether the cognitive system capitalizes on the specific prime-target relation present on the majority of trials. To this end, rather than receiving semantic primes on $80 \%$ of trials, subjects in the high-RP group of Experiment 2 received repetition primes on $60 \%$ of trials and, like subjects in the low-RP group, received semantic primes on $20 \%$ of trials.

If the cognitive system is sensitive to the specific nature of the dominant prime-target relation, then semantic priming in the high-RP group in Experiment 2 might not benefit from the presence of a large proportion of repetition primes because the dominant prime-target relation would be one of repetition rather than semantic relatedness. If the system instead becomes tuned to the overall frequency with which primes tend to be useful for target processing, then the presence of many repetition-primed targets should increase the use of primes even on semantically primed trials, producing once again an increase in semantic priming. In either case, explanations that rely on subjects using expectancy or semantic matching strategies would not predict an influence of RP on semantic priming here because of the brief SOA and masked presentation of primes and because the majority of trials in the high-RP group involve repetition primes, which would lead subjects to expect the wrong kind of target on semantic prime trials (i.e., a repetition of the prime).

\section{Method}

Subjects. Forty subjects from the University of Victoria pool participated. Half were randomly assigned to each RP group.

Materials, Design, and Procedure. This experiment was different from Experiment 1 in two respects. First, in the high-RP group, rather than assigning four of the five blocks of items to the related-prime condition, three blocks were assigned repetition primes $(60 \%)$, one block was assigned semantically related primes $(20 \%)$, and the fifth block was assigned unrelated primes (20\%). For the low-RP group, one block was assigned semantically related primes $(20 \%)$ and the remaining blocks were assigned unrelated primes $(80 \%)$. For both groups, assignment of blocks of items to priming conditions was counterbalanced across subjects. Second, the nonwords in the low- and high-RP groups were assigned repetition and unrelated nonword primes in ratios of $.2: .8$ and $.8: 2$, respectively, as was typically done in the masked repetition priming experiments in Bodner and Masson (2001). We ran Experiment 2 prior to Experiment 1B and hence did not include the prime classification and identification task.

\section{Results}

Response latencies were truncated, as in Experiment 1, removing fewer than $0.5 \%$ of the trials. The mean response latency and error percent for words and nonwords are shown in Figure 2.

Word targets. Semantic priming in the high-RP and low-RP groups was assessed by an ANOVA with RP group and prime (semantic, unrelated) as factors. The overall response latency advantage for the high-RP group over the low-RP group apparent in Figure 2 did not reach significance $\left[F(1,38)=3.31, M S_{\mathrm{e}}=15,264, p<.10\right]$, but there was a significant 23 -msec semantic priming effect $\left[F(1,38)=19.09, M S_{\mathrm{e}}=549\right]$. Most important, the interaction between group and prime was significant $[F(1,38)=$ $5.24, M S_{\mathrm{e}}=549$ ], indicating that semantic priming was larger in the high-RP group. Pairwise comparisons revealed that semantic priming was significant when $R P$ was high $(35 \mathrm{msec})\left[F(1,19)=26.07, M S_{\mathrm{e}}=631\right]$, but not when RP was low $(11 \mathrm{msec})(F<1.89)$. The lack of significant semantic priming in the low-RP group was due to greater inconsistency across subjects than was seen in Experiment 1 with respect to the priming effect. This inconsistency meant that power to detect a priming effect of the same magnitude as that found in Experiment $1 \mathrm{~A}(14 \mathrm{msec})$ among low-RP subjects in Experiment 2 was only .17. 


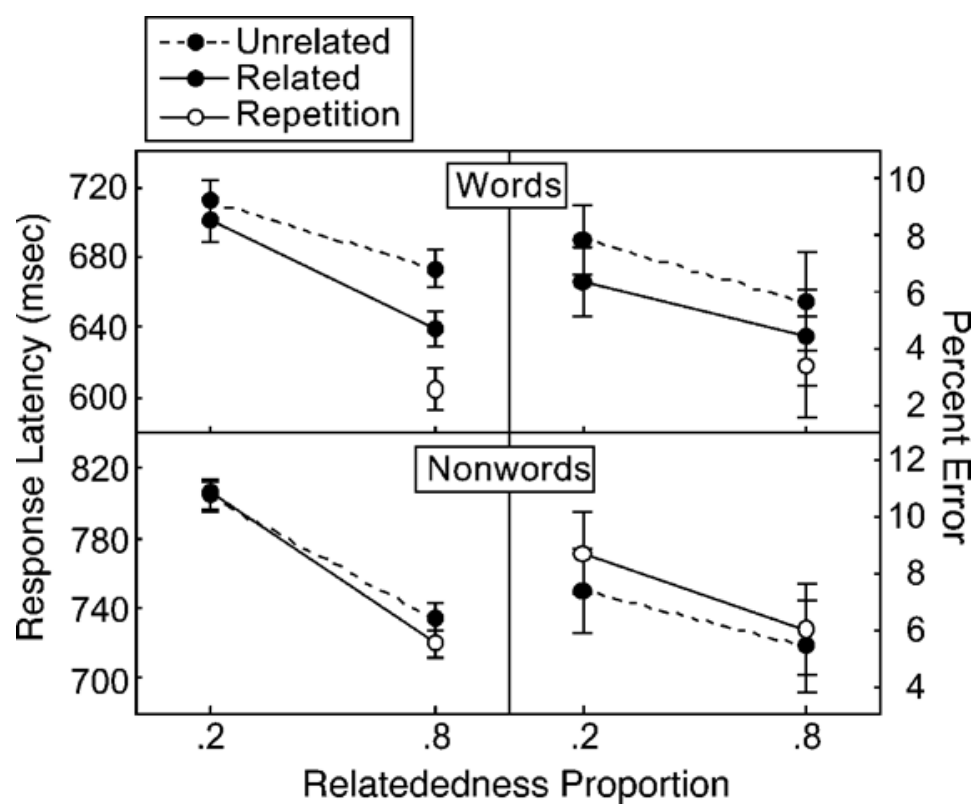

Figure 2. Mean response latency and percent error for words and nonwords in Experiment 2. Error bars are $95 \%$ within-subjects confidence intervals and are appropriate for comparing means across prime conditions within each $\mathbf{R P}$ group. For word targets, confidence intervals were computed separately for related and repetition primes.

Twenty percent of the low-RP group and $25 \%$ of the high$\mathrm{RP}$ group reported having some awareness of the primes (typically a minimal amount). As in Experiment 1, when these prime-aware subjects were excluded, the semantic priming advantage for the high-RP group over the low-RP group (36 vs. $7 \mathrm{msec}$ ) was not eliminated despite the loss of power $\left[F(1,28)=5.11, M S_{\mathrm{e}}=599\right]$.

The error analysis yielded marginal effects of RP $\left[F(1,38)=2.98, M S_{\mathrm{e}}=29.6, p<.10\right]$ and semantic priming $\left[F(1,38)=3.55, M S_{\mathrm{e}}=10.4, p<.10\right]$, which did not interact $(F<1)$.

The 69-msec repetition priming effect in the high-RP group $\left[F(1,19)=77.11, M S_{\mathrm{e}}=617\right]$ was accompanied by marginally fewer errors on repetition trials than on unrelated trials $\left[F(1,19)=3.52, M S_{\mathrm{e}}=14.8, p<.10\right]$.

Nonword targets. Response latencies to nonwords were reliably shorter in the high-RP group than in the low$\mathrm{RP}$ group $\left[F(1,38)=5.46, M S_{\mathrm{e}}=22,039\right]$. There was a 7-msec repetition priming effect that approached significance $\left[F(1,38)=3.32, M S_{\mathrm{e}}=295, p<.10\right]$, and that was qualified by a reliable interaction of priming with RP $\left[F(1,38)=4.39, M S_{\mathrm{e}}=295\right]$. Post hoc tests showed that there was a significant $15-\mathrm{msec}$ repetition priming effect in the high-RP group $\left[F(1,19)=7.95, M S_{\mathrm{e}}=305\right]$ and a nonsignificant difference of $1 \mathrm{msec}$ in the low-RP group $(F<1)$ that favored the unrelated-prime condition. This interaction approached significance when prime-aware subjects were excluded from the analysis ( $14 \mathrm{vs} .-2 \mathrm{msec}$ ) $\left[F(1,28)=3.09, M S_{\mathrm{e}}=313, p<.10\right]$. In several experiments, Bodner and Masson (2001) found a prime validity effect for nonwords, though only when a 60 -msec SOA was used. When prime validity is high, increased reliance on primes may facilitate encoding of nonword targets on repetition prime trials, thus allowing more rapid nonword decisions to be made. There were no significant effects in the error rate analysis.

\section{Discussion}

Semantic priming was once again greater in the highRP group than in the low-RP group. This time, an increase in semantic priming was brought about by presenting a high percentage of repetition primes, rather than a high percentage of semantic primes, to the high-RP group. This result suggests that enhanced reliance on masked prime resources operates in a rather general manner, making use of whatever relation holds between a related prime and target.

In contrast to our finding of positive priming for both semantic and repetition primes, Kahan (2000, Experiment 2) found that when masked semantic and repetition primes were mixed, positive priming for both prime types occurred when subjects were able to identify the prime. In that experiment, subjects attempted to identify the prime before naming the subsequent target. When identification failed, however, positive priming was found with semantic primes but negative priming was found with repetition primes. Although it is not clear why our results differ from those reported by Kahan, we suspect that the reason has to do with the requirement in Kahan's experiment that subjects attempt to identify the prime on each trial before re- 
sponding to the target. In contrast, our subjects typically remained unaware of the presence of primes while responding to targets.

We note that subjects in the high-RP group were generally faster in making their responses than were subjects in the low RP-group. As a result, the influence of increased $\mathrm{RP}$ was apparently one of speeded responding on both related and unrelated trials. This outcome contrasts with the cost-benefit pattern seen when the results of Experiments $1 \mathrm{~A}$ and $1 \mathrm{~B}$ were combined and when Bodner and Masson (2001) combined data across multiple experiments on masked repetition priming. Although it remains to be investigated, the preponderance of repetition-prime trials in the high-RP group may have induced this group to generally respond more quickly than subjects in the low-RP group, perhaps by influencing subjects' decision criteria (e.g., Lupker, Brown, \& Colombo, 1997).

As in Experiment 1, exclusion of prime-aware subjects did not reduce the influence of RP on priming, thereby obviating the possibility that this effect was generated by expectancy or other conscious strategy. Moreover, had the high-RP group used an expectancy strategy, the most reliable expectation would have been that the target would be a repetition of the prime, because repetition prime trials were the most frequent type of prime presented to that group. This expectation would have been violated when semantically related prime-target pairs were presented, which would work against finding enhanced semantic priming in the high-RP group.

\section{GENERAL DISCUSSION}

The interaction between RP and masked semantic priming found in these experiments is a striking outcome, given previous null effects of RP at short SOAs (e.g., den Heyer, Briand, \& Dannenbring, 1983; Hutchison et al., 2001; Perea \& Rosa, 2002; Stolz \& Neely, 1995). We suggest that those null effects may have arisen because awareness of primes may be a source of distraction to subjects when the SOA is too brief to allow subjects to profit from their awareness (Durante \& Hirshman, 1994; Fischler \& Goodman, 1978). In line with this argument, the RP effects on semantic priming reported here were not attenuated when prime-aware subjects were excluded from analyses, and better performance in a prime-awareness task was not associated with larger semantic priming effects (Experiment 1B). Our use of a strong RP manipulation and the slight degradation engendered by flanking our targets with ampersands may have contributed to the RP effect we observed. But in any event, prior studies showing null effects of RP at short SOAs do not render our results implausible.

The finding that RP can modulate masked semantic priming when a 45-msec SOA is used questions the generality of the claim that RP influences priming only through consciously deployed strategies such as expectancy or semantic matching (e.g., Neely, 1991; Neely \& Keefe, 1989). Our results warn against treating RPmodulated priming as diagnostic of consciously controlled strategies. The sensitivity of masked semantic priming to
RP also cannot readily be explained by spreading activation accounts, given the prospective, automatic nature of this mechanism. On the other hand, retrospective accounts of priming that view prime events as creating a form of episodic resource that can be recruited to assist with target processing are supported by the present results (e.g., Bodner \& Masson, 1997, 2001; Whittlesea \& Jacoby, 1990).

Finally, Stolz and Neely's (1995) activation-based account of RP effects may provide a second plausible explanation of the present results. Their account makes use of the concept of feedback between levels in a multilevel activation model (see Besner \& Smith, 1992, for details). In this model, a semantic prime activates its entry in an orthographic lexicon, which then feeds forward to activate its entry in a semantic module. Activation spreads to related words in the semantic module, providing one locus for semantic priming. Activation from these related words can then feed backward to activate their entries in the orthographic lexicon, providing a second locus for semantic priming. Stolz and Neely suggested that modulation of priming effects would result if feedback were to occur only when RP is high (e.g., to conserve activation in the system). The introduction of modifiable contributions of feedback to priming may prove to be a useful way of characterizing the influence of RP on masked semantic priming within an activation-based account.

\section{REFERENCES}

Allen, S. W., \& JACobY, L. L. (1990). Reinstating study context produces unconscious influences of memory. Memory \& Cognition, 18, 270-278.

Anderson, J. R. (1983). The architecture of cognition. Cambridge, MA: Harvard University Press.

BeSNER, D., \& SMITH, M. C. (1992). Models of visual word recognition: When obscuring the stimulus yields a clearer view. Journal of Experimental Psychology: Learning, Memory, \& Cognition, 18, 468-482.

Bodner, G. E., \& Masson, M. E. J. (1997). Masked repetition priming of words and nonwords: Evidence for a nonlexical basis for priming. Journal of Memory \& Language, 37, 268-293.

Bodner, G. E., \& Masson, M. E. J. (2001). Prime validity affects masked repetition priming: Evidence for an episodic resource account of priming. Journal of Memory \& Language, 45, 616-647.

Collins, A. M., \& LofTus, E. F. (1975). A spreading-activation theory of semantic processing. Psychological Review, 82, 407-428.

Dehaene, S., Naccache, L., Le Clec'H, G., Koechlin, E., Mueller, M., van de Moortele, P., \& Le Bihan, D. (1998). Imaging unconscious semantic priming. Nature, 395, 597-600.

den Heyer, K., Briand, K., \& Dannenbring, G. (1983). Strategic factors in a lexical decision task: Evidence for automatic and attentiondriven processes. Memory \& Cognition, 11, 374-381.

Durante, R., \& Hirshman, E. (1994). Retrospective priming and masked semantic priming: The interfering effects of prime activation. Journal of Memory \& Language, 33, 112-127.

Fischler, I., \& Goodman, G. (1978). Latency of associative activation in memory. Journal of Experimental Psychology: Human Perception \& Performance, 4, 455-470.

Henik, A., Friedrich, F. J., Tzelgov, J., \& Tramer, S. (1994). Capacity demands of automatic processes in semantic priming. Memory \& Cognition, 22, 157-168.

Hutchison, K. A., Neely, J. H., \& Johnson, J. D. (2001). With great expectations, can two "wrongs" prime a "right"? Journal of Experimental Psychology: Learning, Memory, \& Cognition, 27, 1451-1463.

JACOBy, L. L. (1983). Perceptual enhancement: Persistent effects of an experience. Journal of Experimental Psychology: Learning, Memory, \& Cognition, 9, 21-38. 
Kahan, T. A. (2000). Negative priming from masked primes: Retrospective prime clarification or center-surround inhibition? Journal of Experimental Psychology: Learning, Memory, \& Cognition, 26, 13921410.

Kouider, S., \& Dupoux, E. (2001). A functional disconnection between spoken and visual word recognition: Evidence from unconscious priming. Cognition, 82, 35-49.

KuČERA, J., \& FranCIS, W. N. (1967). Computationalanalysis of presentday American English. Providence, RI: Brown University Press.

Loftus, G. R. \& Masson, M. E. J. (1994). Using confidence intervals in within-subject designs. Psychonomic Bulletin \& Review, 1, 476-490.

Lupker, S. J., Brown, P., \& Colombo, L. (1997). Strategic control in a naming task: Changing routes or changing deadlines? Journal of Experimental Psychology: Learning, Memory, \& Cognition, 23, 570-590.

Masson, M. E. J., \& ISAAK, M. I. (1999). Masked priming of words and nonwords in a naming task: Further evidence for a nonlexical basis for priming. Memory \& Cognition, 27, 399-412.

McNamara, T. P. (1992). Priming and constraints it places on theories of memory and retrieval. Psychological Review, 99, 650-662.

Meyer, D. E., Schvaneveldt, R. W., \& Ruddy, M. G. (1975). Loci of contextual effects on visual word-recognition. In P. M. A. Rabbitt \& S. Dornic (Eds.), Attention and performance $V$ (pp. 98-118). New York: Academic Press.

Naccache, L., \& Dehaene, S. (2001). Unconscious semantic priming extends to novel unseen stimuli. Cognition, 80, 215-229.

NeELY, J. H. (1991). Semantic priming effects in visual word recognition: A selective review of current findings and theories. In D. Besner \& G. W. Humphreys (Eds.), Basic processes in reading: Visual word recognition (pp. 264-336). Hillsdale, NJ: Erlbaum.

Neely, J. H., \& Keefe, D. E. (1989). Semantic context effects on visual word processing: A hybrid prospective/retrospective processing the- ory. In G. H. Bower (Ed.), The psychology of learning and motivation: Advances in research and theory (Vol. 24, pp. 207-248). New York: Academic Press.

Neely, J. H., Keefe, D. E., \& Ross, K. (1989). Semantic priming in the lexical decision task: Roles of prospective prime-generated expectancies and retrospective semantic matching. Journal of Experimental Psychology: Learning, Memory, \& Cognition, 15, 1003-1019.

Perea, M., \& Gotor, A. (1997). Associative and semantic priming effects occur at very short stimulus-onset asynchronies in lexical decision and naming. Cognition, 62, 223-240.

Perea, M., \& Rosa, E. (2002). Does the proportion of associatively related pairs modulate the associative priming effect at very brief stimulusonset asynchronies? Acta Psychologica, 110, 103-124.

Ratcliff, R. \& McKoon, G. (1988). A retrieval theory of priming in memory. Psychological Review, 95, 385-408.

SERENO, J. A. (1991). Graphemic, associative, and syntactic priming effects at a brief stimulus onset asynchrony in lexical decision and naming. Journal of Experimental Psychology: Learning, Memory, \& Cognition, 17, 459-477.

Stolz, J. A., \& Neely, J. H. (1995). When target degradation does and does not enhance semantic context effects in word recognition. Journal of Experimental Psychology: Learning, Memory, \& Cognition, 21, 596-611.

UlRich, R, \& Miller, J. (1994). Effects of truncation on reaction time analysis. Journal of Experimental Psychology: General, 123, 34-80.

WhittleseA, B. W. A., \& JACOBY, L. L. (1990). Interaction of prime repetition with visual degradation: Is priming a retrieval phenomenon? Journal of Memory \& Language, 29, 546-565.

(Manuscript received November 2, 2001; revision accepted for publication April 5, 2002.) 